\title{
Human Rights-Based Approach to Disaster Management: Valparaiso, Chile
}

\author{
Karen Rice $^{1}$ (D) Marc V. Felizzi ${ }^{1}$ - Duane Hagelgans ${ }^{1}$
}

Published online: 4 October 2017

(C) Springer International Publishing AG 2017

\begin{abstract}
An overview of the devastating April 2014 wildfire that destroyed a large number of homes and killed 15 people in the communities surrounding Valparaiso, Chile, is provided. Utilizing a human rights-based framework, a qualitative study was conducted 6 months after the disaster to examine the community's response. Interviews were held with formal and informal community leaders, as well as community organizers and members of the Pontificia Universidad Católica de Valparaiso (PUCV). These interviews depicted a number of interrelated variables and, most notably, a strong sense of community emerged, which was consistent with the informal system in place among the residents of the Upper Hills. This informal support system emerged over the years due to a lack of capacity in place by the local government. The findings of this study could be held as an example for other communities who find little support or resources from their local governments. Findings from the research provide direction and steps to enhance preparedness and build capacity for communities, especially in times of both man-made and natural disasters.
\end{abstract}

Keywords Human rights-based perspective $\cdot$ Chile · Emergency management $\cdot$ Natural disaster

\section{Karen Rice}

Karen.rice@millersville.edu

1 Millersville University, Millersville, USA

\section{Rights-Based Approach to Disaster Management: Rural Valparaiso, Chile}

Valparaiso is a "City of Hills." The surrounding villages and neighborhoods of Chile's major port and second largest city are situated on 42 hills overlooking the city and Pacific Ocean. The views are breathtaking, and the neighborhoods are rich in cultural artifacts and colorfully painted homes. In 2003, Valparaiso was named a United Nations Educational, Scientific, and Cultural Organization (UNESCO, 2003) World Heritage Site because of its significance as a port. Also in 2003, the community of the Upper Hills, East and North of Valparaiso, and separated from the city by one-lane winding and twisting roads, was named a World Heritage Site (Castillo, Quintanilla, \& Guillermo, 2012). This description occurred due to the historic nature and uniqueness of the Upper Hills community. The UNESCO designation assists the metropolitan area of Valparaiso with its preservation of this significant port city and with assistance in rebuilding the port city after this devastating fire (UNESCO, 2014). The UNESCO designation as a World Heritage Site does not assist or address the needs of the residents in the Upper Hills region where many of Valparaiso's poorest citizens reside. Only the areas where the port city expanded into the hills with cathedrals, markets, and squares are part of the World Heritage site (UNESCO, 2003). With little, if any government or outside support, as will be explained, these residents truly accomplished a human rights-based approach to rebuilding their unincorporated communities, thus being a model that communities around the world can imitate, deciding their own fate, rather than leaving it in the hands of government. 
The Upper Hills neighborhoods comprise homes are literally built on top of one another on the sides of hills, and are accessed by narrow, winding unpaved streets. The homeowners are collectively known as "squatters" because they have no title to their land, and vacant lots for claimed as individuals migrate to the neighborhood (Castillo, et al., 2012). The local governments recognize the residents' need to squat on the land, and have adopted a policy of benign neglect towards the neighborhoods (Reska \& Fuentes, 2015). The homes on the hills were built using substandard methods, are close in proximity to one another, rely heavily on the use of lightweight construction materials with no official approvals, and have poor access to basic services such as water and electricity. Further, the fuel load in this area is high because of the close proximity of the homes to pine and eucalyptus forests, the accumulation of trash in empty fields and dried up ravines, as well as "jerry-rigged" electrical lines tapped from municipal power lines adding to the fire hazards (Reska \& Fuentes, 2015).

The Upper Hills neighborhoods are a reflection of the economic inequality evident in the Chilean nation (Jarroud, 2014). While affluence and comfort are evident surrounding the city in the lower hills neighborhoods, central Valparaiso and the seaside community of Viña del Mar, the Upper Hills community suffers from the lack of economic, material, community, and utility resources. Additionally, the area where the fire was reported to have started was a trashfilled gulch that contained invasive, fast-burning trees such as eucalyptus and scrub pine. Pine and eucalyptus are especially flammable as they are rich in volatile resins that light up easily. Much of this vegetation took over these areas after the native species were used for timber production (Homad-Hanan, 2009). The Upper Hills, like many disadvantaged regions in the Central Valley, were overharvested and deforested during the authoritarian regime of General Augusto Pinochet; this region lost 38\% of its forests between 1975 and 2009 (Homad-Hana, 2009). Like many impoverished areas throughout the world, the residents of the Upper Hills neighborhoods rely on nature to provide many of their resources, using cisterns to collect rainwater and the many ravines scattered throughout the area to dump their garbage and household refuse. Many residents of the Upper Hills lack indoor plumbing and have difficulty accessing services such as physical and mental healthcare, food stores, and utilities. The residents of the Upper Hills barely have the means to survive, when coupled with their substandard living conditions and dangerous location, and they are the most vulnerable population in the Valparaiso region of Chile. The economic inequality is a contradiction with regard to Chile's status as a member of the Organisation for Economic Co-operation and Development (OECD). As one of the most developed nations, with the most robust economy in South America
(OECD, 2017), there still are areas, such as the Upper Hills, where citizens do not have the basic necessities, such as running water.

The number of destructive wildfires in Child has increased in the last 20 years. Researchers speculate one of the reasons is due to the proliferation of eucalyptus and pine trees, which, as stated earlier, are invasive vegetation that takes over deforested regions, which are plentiful in the Central Chilean region. These trees have a root system that drains most of the groundwater in the area, leaving behind dry gulches full of fuel (National Geographic, 2017). In addition to deforestation and the proliferation of pine and eucalyptus trees, researchers have pointed towards the intense heat of the last several summers, some of which have broken temperature records in Chile (Martinez, 2017). Since early 2017, Chilean wildfires have overrun towns, displaced thousands of residents, and depleted firefighting budgets. The smoke and the scar of the fire are visible and evident throughout the central region (Martinez, 2017).

The "Great Fire," which started on April 12, 2014, in the Upper Hills neighborhood, claimed 15 lives, destroyed 2500 homes, and left 11,000 residents homeless (Bonnefoy, 2014). The origin of the fire is still under investigation. Several possible causes of the fire have been suggested, although no one origin has been pinpointed. It has been confirmed that the fire accelerated after trash and vegetation fed the flames in one of the numerous ravines in the community (Bonnefoy, 2014). The fire spread, in part, because of the dry, 26-mph winds in the area. Many of the homes in the area, which were not built according to local building or fire codes, immediately went up in flames and added to the conflagration (Bonnefoy, 2014). About 2500 acres of land were affected as a result of the fire.

In addition, the fire destroyed several power-generating stations and caused outages throughout Valparaiso and the surrounding communities. President Michele Bachelet called the disaster "the worst fire in Valparaiso's history" (Bonnefoy, 2014). The Chilean Army and National Guard were ordered to preserve order and assist with the evacuation of residents.

The current study was formed as a collaboration between the School of Social Work and the Center for Disaster Research and Education (CDRE) at a Mid-Atlantic University, and Pontificia Universidad Católica de Valparaiso (PUCV). The intent was to provide PUCV with consultation regarding the disaster response to the communities affected by the fires, as well as to the social workers who work with the victims of the fire. The needs of the social workers whose clients live in the Upper Hills communities were addressed by discussing the physical, emotional, and psychological trauma of the disaster. In addition, community members, formal and informal leaders, as well as the social workers who practice in the community were interviewed as part of this study.

From a human rights-based perspective, the findings of the study will add to a body of literature that is deficient in research 
addressing the needs and rights of victims of a disaster. While not perfect, the Universal Declaration of Human Rights (UDHR) offers principles that everyone, regardless of where they reside, should enjoy in order to advance their rights (United Nations, 1948). The UDHR is subject to interpretation; however, the document offers principles around fundamental freedoms and rights that can be applied to any set of circumstances (Reichert, 2011), including natural disasters.

Although this research study examined one specific international disaster, the implications are applicable to any global setting. In addition, suggestions will be offered for social workers who intervene with citizens in communities that have been affected by disasters and are further impeded from recovery by a lack of resources and government assistance. This is done by examining the response to the fire's devastation in the Upper Hills neighborhoods through a human rights-based perspective. Utilizing one specific human rights-based framework that was applied when examining the disaster response in Haiti, the ideals of equality, transparency, accountability, and empowerment will be explored (Ensor, Hoddy, \& Ratnor, 2015). Specifically, equality refers to ensuring those in need receive the resources they are entitled to, while transparency ensures those affected by the disaster have full access to information in order to make informed decisions. Accountability refers to holding those with power and ability to distribute those resources responsible for doing so. While distributing resources and rebuilding post disaster, it is essential that those affected are empowered through participation in the recovery in order to ensure sustainable effects.

Human rights-based approaches are considered consistent with the core values of social work in that such a methodology incorporates the values of social justice, the importance of human relationships, service to others, and the dignity and worth of all citizens (National Association of Social Workers, 2008). The significant growth of vulnerable populations such as those living in the Upper Hills of Valparaiso, during the last 25 years, has promoted social work into providing leadership, nationally. The Seguridad Educacional Integral (SEI) Chile Foundation, established in 2014 by a group of social workers, lawyers, administrators, and teachers, promotes the value of social workers in Chile. One of the goals of this organization is to enhance professional performance at the practice level. In addition, the SEI Chile appears to align with the precepts of a human rights-based approach by promoting both social change and social justice, along with an inclusion of all stakeholders in the community to improve the delivery of mental health services (Social Work Management, 2015).

\section{Literature Review}

A review of the extant literature that focuses on disaster preparedness in communities reveals an emphasis on resilience of the citizens of the affected area and of the community in general (Gibbs, et al., 2013; Manyena \& Gordon, 2015; Townshend, 2015; Ward, et al., 2015). Resilience, while an intangible concept, tends to be defined by the ability of a community to either "bounce back" to pre-disaster levels of daily living or to become stronger and to develop more effective coping skills in the event of a subsequent crisis or disaster. Resilience, as defined by the literature, also takes into account the ability to create more effective prevention planning and community education regarding natural or man-made disasters (Arouri, Nguyen, \& Youssef, 2015; Barrios, 2014; Bergstrand, Mayer, Brumback, \& Zhang, 2015; Cox \& Hamlen, 2015; Cutter, Ash, \& Emrick, 2014; Fernando, 2012; Korstanje, 2014; Magsino, 2009; Sandoval, GonzalezMuzzio, \& Albornoz, 2014; Xin, Aronson, Lovelace, Strack, \& Villalba, 2014).

A community prepared to effectively respond to a natural disaster will have a disaster response plan in place. A successful disaster response is one that places the rights of humans at the center. According to the United Nations High Commissioner for Human Rights (2013), employing a human rights-based approach during a disaster response ensures that plans, policies, and processes of international assistance adhere to rights and obligations outlined by international law and human rights treaties. A rights-based approach to disaster preparedness, response, and recovery has both intrinsic and extrinsic values. Intrinsically, it recognizes individuals affected by disaster as "rights-holders with entitlements" (United Nations High Commissioner for Human Rights, 2013); therefore, framing the approach to assistance as collaborative rather than charitable or needs based. Doing so places value on the individual not just having a specific right to assistance as a member of society but as having a right to voice and guide how the response and recovery should occur. Extrinsically, a human rights-based approach strengthens community because individuals affected by disaster, when collaboratively engaged during the planning, response, and recovery stages, build capacity to meet future needs and contribute positively to the enhancement of society (United Nations High Commissioner for Human Rights, 2013). These results are accomplished by designing and delivering disaster assistance in a way that prioritizes five key components: capacity building, participation, transparency, accountability, and nondiscrimination (Human Rights Center, 2011).

One example of this approach is discussed in Johnson's (2010) research in Nepal, which addressed cultural issues surrounding extreme poverty in the country. A human rights-based perspective drove the interventions used with children in the Nepalese communities. Prior to developing child-focused and rights-based programs, young people in Nepal tended to be marginalized, with their perspective given little acknowledgement when programs that affected them were enacted. Throughout the project, children were 
consistently consulted and interviewed to provide their perspective for informing policy and community development, and many expressed their needs, wants, and rights in order to create effective policies that addressed the younger citizens' issues (Johnson, 2010).

Ensor et al. (2015) examined the application of a human rights-based perspective within a rural agricultural community in East Timor. The researchers created an analytical program to examine the community's capacity to adapt to climate change. The analysis sought to examine perceptions of accountability, transparency, equality, and empowerment in the rural community. Utilizing a human rights-based perspective, rural Timorese were able to participate in program development addressing climate change. Rather than the government applying a program to address change, citizens added their voices to the change model and were able to address, collaboratively across political, social, and technological areas, the effects of climate change and creeping urbanization effects on farmers in the rural Timorese community.

As previously mentioned, human rights-based approach aligns with social work values of social justice, the importance of human relationships, service to others, and the dignity and worth of all citizens, and therefore, this research study adds to the growing body of literature related to human rights-based practice in social work.

\section{Methodology}

As the researchers of this study sought to understand how one community responded following a natural disaster, it was imperative to acquire an insider's view, and therefore, those involved in the response efforts, as well as those affected, were engaged in order to obtain this emic perspective. A qualitative research design was employed, specifically a single-case design case study as this is the preferred methodology when attempting to understand complex social phenomenon that cannot be manipulated (Yin, 2009), such as a community's response to a natural disaster. Permission to conduct the study, which ensured the protection of the human subjects being studied, was obtained by the authors' University's Institutional Review Board.

\section{Sample}

The unit of analysis was the Upper Hills of Valparaiso, Chile. There are 42 hills located in Valparaiso. Seven of the hills were affected by the fires, but only three of the hills make up the unit of analysis: Las Cañas, El Vergel, and El Litre. These hills were selected as they experienced the majority of the damage from the fire. Our colleagues in the psychology and social work programs at PUCV made prior arrangements for our research team to visit various community centers within the hills, fire departments, and public social service organizations. The staff, volunteers, and firefighters present during our visit became part of the sample. Using university approved and paid interpreters, verbal consent to participate in the interviews and/or focus groups, for the purpose of this study, was obtained prior to proceeding with asking questions, conducting observations, or reviewing documents.

\section{Data Collection}

In October 2014, a group of six faculty members from various departments within one Mid-Atlantic public institution of higher education, embarked on a week-long trip to Valparaiso, Chile. The intent of the trip was to collaborate with PUCV, to address the fire, emergency, meteorological, and mental health responses to the April 2014 wildfires, which ravaged many of the Upper Hills neighborhoods surrounding the city. During the week-long trip, 5 days were spent collecting data from the individuals identified above.

As stated, a case study research design was employed to understand Chile's response to the April 2014 wildfires. According to Yin (2009), a single-case study design is best suited in this situation due to the extremity of the case and, therefore, importance to document and analyze. Additionally, single-case studies are relevant when testing a well-formulated theory (Yin, 2009) such as the human rights-based approach, which is the framework used in this study. Multiple methods of data collection were employed to ensure rigor as not one individual's perspective comprised the findings from this study. These methods included in-depth individual interviews, focus groups, direct observations, and document analysis. Indepth interviews with 12 individuals, and 4 separate focus groups comprising 30 total individuals were the primary data collection method employed as the focus groups allowed for an increase in the number of community members from whom data were collected. Further, these interviews (in-depth and focus groups) occurred in the natural environment of the participants, which allowed for additional data collection, specifically direct observations of the recovery efforts. Documents obtained and examined included ten different newspaper articles reporting the fire and response/recovery efforts, which the researchers obtained through an independent online search of articles and newspaper reports; five nongovernmental organization (NGO) treatment manuals, which were provided to the research team during our visit; and three fire department logs from the day the fire started, which we were able to observe during our visit to the fire departments. Table 1 summarizes the data collection plan, including data collected, method for collecting data, person from whom data collected, and length of data collection process. 
Table 1 Summary of data collection plan

\begin{tabular}{|c|c|}
\hline Data collection source & Data collection method \\
\hline PUCV psychology, law, and social work faculty $(N=6)$ & Focus group ( $2 \mathrm{~h}$ in length) and documents \\
\hline PUCV psychology and social work students $(N=10)$ & Focus group (1 h in length) \\
\hline Valparaiso's fire departments' firefighters $(N=6)$ & $\begin{array}{l}\text { In-depth interviews ( } 1 \mathrm{~h} \text { in length with Fire Chief and one firefighter), } \\
\text { focus group ( } 1 \mathrm{~h} \text { in length), and documents }\end{array}$ \\
\hline $\begin{array}{l}\text { Mental health workers (psychologists and social workers) } \\
\text { from various NGOs }(N=8)\end{array}$ & Focus group ( $1 \mathrm{~h}$ in length) and documents \\
\hline Community center employees $(N=5)$ & In-depth interviews (30-60 min in length) and documents \\
\hline Upper Hills residents $(N=5)$ & Direct observations and in-depth interviews (30 min in length) \\
\hline
\end{tabular}

\section{Analysis}

A theoretical approach, specifically a human rights-based approach to disaster response, was used as the framework to analyze the data collected, which is the preferred data analysis strategy in case study research (Yin, 2009). This approach ensures the focus on relevant data in order to answer the research question. The specific data analysis technique employed was pattern matching, which seeks to identify patterns across data collection methods (Trochim, 1989). This analytical technique can help strengthen the internal validity of case study research designs (Yin, 2009). This is done by using the theoretical concepts, in this case, the human rights-based framework concepts to focus on the most relevant data and organize the entire case study when reporting findings (Yin, 2009). Using NVivo 9.0 (QSR International, 2011), the first author initially sorted datum into patterns that appeared to represent one of the key principles of the human rights-based framework. Following this initial coding, the three authors undertook a second round of coding, comparing, and contrasting the datum sorted into each category to ensure the datum represented the key theoretical principles guiding the data analysis (Denzin \& Lincoln, 2005). The key theoretical concepts used in this study were capacity building, participation, accountability, transparency, and nondiscrimination (Concannon \& Lindstrom, 2012). Therefore, the analysis involved a comparison of the data collected to the predicted patterns (theoretical key concepts), in addition to identification of any variances or gaps.

\section{Findings}

\section{Capacity Building}

Capacity building refers to putting the infrastructure in place to respond to the needs of all its citizens during a natural disaster (Concannon \& Lindstrom, 2012). The all-volunteer firefighting forces of Valparaiso are a very proud and historic department that was a key to controlling the fire in such a rapid manner. Firefighting, which by law is performed by volunteers, has a long history in Chile with each new immigrant group settling in the area, establishing its own fire department. However, there are no fire stations within the hills or water tanks in the Upper Hills. Despite the environmental conditions of the Upper Hills (narrow, steep roads; lack of water), and the wind speeds the day of the fire, the well-trained fire brigade comprised of 16 fire stations, 400 firefighters, 45 engines, 6 ladder trucks, 5 rescue vehicles, and 38 water tankers battled the fire by heading straight to the source, the top of the hills. By responding in such an organized fashion, most of the fire was extinguished within 32 hours after it started. According to the fire department of Valparaiso, they are well regarded by its citizens. During a focus group interview with the firefighters, they reported that $99.9 \%$ of citizens who completed a recent survey believed the fire department to be credible, for four straight years.

Despite most of the citizens positively regarding the fire department, this did not prevent the firefighters from experiencing some resistance as they made their way up the hills on the evening of the fire. A firefighter reported some citizens "threw rocks at the fire trucks and attempted to stop them from navigating further up" the steep hills. The resistance the firefighters experienced during the government disaster intervention may be due to the residents of the rural Upper Hills feeling a "lack of support and help receive from the city." Following the extinguishing of the fire, many residents continued to resist assistance from the groups converging on the Upper Hills to assist in the recovery process.

It was the expectation that the Chilean government would play a central role in responding to the needs of the residents in the Upper Hills; however, the response was slow. During interviews with staff at the state-run social service center, we learned that the center helped approximately 20,000 residents of the Upper Hills; however, the residents had to "voluntarily seek assistance from the center." The primary role of the government center, following the fire, was to distribute donated food to the residents of the Upper Hills, as well as to assist residents with obtaining documents lost 
in the fire; however, as we learned, this process would occur when residents sought assistance. Even then, there was insufficient food and the process to recover destroyed documents was not timely.

The Red Cross also provided immediate aid to residents. As many of the schools burned down or were turned into shelters, the Department of Education provided financial support to PUCV to create psychosocial teams consisting of psychology and social work students to coordinate efforts to provide services to children; however, they too were met with resistance as residents of the Upper Hills did not want to seek help as they did not view themselves as "victims." It was shared by the psychosocial teams that the residents have learned to respond to past trauma (e.g., lack of housing, lack of income, injury) without government intervention and assistance; therefore, they did not view themselves as needing outside help following the fire, despite its devastation to the area.

Despite having a government social service system in place, officials were not responsible for coordinating efforts among those who converged on the Upper Hills to help. Therefore, residents responded as they often did during times of need - by coordinating efforts from within. During times of crisis, the informal leaders of the community convene to assess the community's need and to determine a course of action. Following the fire, the leaders organized efforts and immediately began taking care of themselves and those within their immediate community (hill). The residents of the Upper Hills viewed their right to remain within their community and not be evacuated or moved to temporary shelters as their human right: "People wanted to provide for themselves." This resistance from outsiders (e.g., recovery responders who did not live in the hills) was perceived as a hindrance to the recovery efforts. The leaders within the hills were able to, within six months of the fire, reopen the community health centers that had burned down, often rebuilding them or building temporary sites on abandoned lots. It was these temporary centers that became the primary distributors of aid, coordinating the ad hoc programs that were set up to ensure efficient and effective distribution of aid.

\section{Participation}

A human rights-based approach to disaster response includes the "active, free, and meaningful participation of all parts of society, including impacted communities, grassroots organizations, minorities, rural populations, and women" (Concannon \& Lindstrom, 2012, p. 1176). As stated above, the residents of the Upper Hills immediately organized following the fires to reclaim "their" land and begin rebuilding. This immediate response included an active resistance to outside help. Houses were still being rebuilt during our trip, but an estimated $70 \%$ of the houses were rebuilt within 6 months of the fire. Efforts to assess need and distribute services were organized by the community centers already in place within the Upper Hills. Four community centers were visited to learn what steps were taken following the fires.

Immediately following the fires, one of the main community centers began assessing the damage and needs of families in the affected areas. Following their assessment, they contacted volunteers and universities who were helping in order to organize efforts and distribute services. In an attempt to meet the emotional needs of the residents, who were resistant to traditional mental health services because of the stigma associated with it, they employed an art therapist as they discovered individuals were more likely to "talk" using the arts. The use of the arts was a recurring theme as the method employed by community centers to deliver mental health treatment. A smaller center that served about 200 individuals offered dance in order to keep the members of its community "distracted." Another community center provided "various activities to kids for distraction, including puppet shows, community journalism, workshops, and craft making." The intent of these activities was to continue to foster community engagement in society, through social activities, despite the social and educational centers being destroyed by the fire.

Healthcare was another service provided by community centers. Following the fire, it was reported by the community center staff that many residents, particularly the elderly, contracted pneumonia and died. It was difficult to provide an estimate due to a lack of infrastructure for reporting and tracking. The deaths, in part, were a result of inadequate housing (lack of roof) and change in temperature (approaching winter season) in the Upper Hills. Some of the centers became temporary shelters for residents, providing housing, food, and clothing. As one individual shared, "Initially following the fire, 70 people stayed here. We received construction material and distributed it to families. We also provided clothing, food, and other essentials to people in the immediate area."

\section{Transparency}

Transparency entails sharing information with those affected to ensure they are able to fully participate meaningfully in decision-making (Concannon \& Lindstrom, 2012). Due to the informal living arrangements within the Upper Hills, the residents tend to, and as reported to us, prefer to meet their own needs rather than rely upon "outsiders" for help. Following the fire, the government attempted to intervene to distribute resources, such as building materials. As there was no mechanism in place to share how the distribution of the resources will occur, residents were often misinformed and relied upon the informal communication channels in place. Further, some of the information reported through the media was inaccurate, causing frustration among the residents and conflict among neighbors over the distribution of resources as 
some were receiving the building materials and others were still waiting. As a result, many centers in the area that were not affected by the fire became distribution centers to ensure residents received food, clothing, and building materials. This was an attempt to offer a coordinated effort to distribution of aid so residents knew where to go for assistance and information. Further, PUCV played an important role in sharing information with the leaders of the Upper Hills and with the community centers because government response was often slow and communication with residents of the Upper Hills was almost nonexistent.

\section{Accountability}

Accountability in a human rights-based framework relates to states setting up systems to ensure human rights are not violated and that redress is provided to those who are wronged (Concannon \& Lindstrom, 2012). Chile has the National Emergency Bureau, Ministry of the Interior (ONEMI), which is equivalent to the US Federal Emergency Management Agency (FEMA) from the standpoint of pre-disaster information distribution. However, unlike FEMA, ONEMI does not appear to be focusing on the rights of the residents affected post disaster (Government of Chile, n.d.). Those affected have reported they "want immediate action and to advocate on their own behalf to feel empowered." As previously stated, the government's response was slow. There was no plan in place to prepare for a disaster of this nature despite the number of fires and risk factors present (e.g., inadequate electrical wiring, trees touching the electrical wires, accumulated trash in the ravines). While both ONEMI and FEMA seem to have similar disaster preparedness missions, FEMA through its "whole community" approach involves private citizens, the private sector, and the public sector in their planning, response, and recovery from disasters, a human rights-based approach to disaster management. Those in the hills have prepared for other disasters such as tsunamis and earthquakes, which was also the primary focus of preparedness within the lower region of Valparaiso.

\section{Nondiscrimination}

When responding to the needs of the residents post disaster, services should be rendered that prohibit the discrimination based on race, sex, age, or other social categories (Concannon \& Lindstrom, 2012). As previously stated, the centers initially focused on meeting the physical needs (e.g., housing, food, clothing) of the residents affected by the fire; however, they also recognized the importance of addressing the mental health needs of the residents. Although mental health services were already in place within the centers prior to the fire, these services were not accepted in the community. The government did fund mental health services at community centers; however, the system is taxed by the heavy need for counseling and associated services. The Junta Nacional de Auxilio Escolar y Becas (JUNAEB) oversees the provision of mental health services to school-age children (Garfin, et al., 2014). The majority of their programs are focused in impoverished neighborhoods such as the Upper Hills. To that end, when the government-funded centers could no longer respond to community mental health need following the 2014 Wildfires, the burden was shifted to individuals and local groups who created their own community centers, which was funded by the residents of those areas. During interviews with the psychosocial team members, we learned that the majority of the mental health challenges among residents of the Upper Hills stemmed from a lack of work and work conditions. It is thought that "the government is ignoring mental health needs as it would require them to respond to the work conditions" of the individuals who reside in the Upper Hills.

\section{Discussion}

In the six short months following one of the most devastating fires in the region of the Upper Hills, Valparaiso, Chile, residents organized to respond to their basic human rights such as food, education, housing, and mental health services. Informal leaders in the area emerged to respond to these rights and offer the infrastructure lacking in the area. However, as the findings revealed, despite the impressive, efficient, and timely response from the residents of the area, the challenges remained given the lack of government accountability to implement a plan that ensures capacity building.

The city of Valparaiso, Chile, along with its various emergency services, government entities, and private sector resources, deals with disaster management on a regular basis, but our findings from the April 12, 2014, "Great Fire of Valparaiso" all point towards disparate preparedness between the citizens of the city and the vulnerable population of the Upper Hills. Failure to engage residents of the Upper Hills in disaster preparedness violates a human rights-based approach to disaster management.

A key to disaster management that is lacking in the area of the Upper Hills is the aspect of disaster preparedness. Disaster preparedness is a comprehensive approach to dealing with a disaster. It starts with training in how to respond to a disaster once it strikes and continues through recovery efforts; disaster response is a continuous process (Gupta, 2015). The International Association of Emergency Managers (IAEM) is the professional organization that develops disaster preparedness and training while certifying emergency managers. In October 2014, the IAEM officially created the Latin American and Caribbean Council of IAEM, with its first regional Director being from Santiago, Chile (IAEM, 2015). 
The IAEM, which was a founding partner in creating the Principles of Emergency Management in 2007, also institutionalizes the human rights-based approach through FEMA's whole community concept. In its principles, a human rightsbased disaster management approach is clearly expressed: comprehensive (emergency managers consider all stakeholders), integrated (emergency managers ensure unity of effort among all citizens), collaborative (emergency managers create and sustain broad and sincere relationships among individuals and organizations to encourage trust, advocate a team atmosphere, build consensus, and facilitate communication), and coordinated (emergency managers synchronize the activities of all relevant stakeholders to achieve a common purpose) (FEMA, 2014). Utilizing the resources of the Latin American and Caribbean Council of IAEM in Santiago, social workers are naturally positioned to utilize their cross-systems collaboration skills and assist residents of the Upper Hills with disaster preparedness plans.

\section{Implications for Social Work Practice}

In order to ensure a community or government is able to respond effectively post disaster, all of its citizens need proper training in disaster preparedness; however, it is the most vulnerable populations who are most adversely affected in a disaster and normally lack the resources necessary to rebuild. Disaster preparedness is a program of long-term development activities whose goals are to strengthen the overall capacity and capability of the country and ensure its ability to manage all types of emergencies (Gupta, 2015). Following the destruction of the community centers as a result of the fire, the residents in the Upper Hills experienced a gap in the recovery effort as the fragile system that was in place to meet residents' needs was no longer there. This system included assistance and counseling from interns at PUCV and from the regional social service workers. Social workers, prior to the fire, worked with Upper Hills' residents to develop community resources, as well as provide mental health counseling for its residents. Many of these services were provided in community centers that were either built hastily or were located in residents' homes. Drawing upon the IAEM's Children in Disaster Caucus (IAEM, 2015), social workers, community centers, schools, and other community leaders within the Upper Hills can educate and train the residents in appropriate disaster preparedness, which includes how to respond following a natural disaster. This education can build capacity, which is an essential aspect of promoting a human rights-based approach in natural disaster preparedness.

Social workers who provide services to those affected by disasters, such as the Upper Hills wildfires, have the ability to learn necessary knowledge and skills essential to work with all who are affected by both natural and man-made disasters. There is an increase recognition, in both Chile and the USA for the need to train social workers in disaster mental health, and many schools of social work, including PUCV and the authors' university, are providing such training, certifications, and/or dual degree programs. Additionally, within the USA, FEMA (2017) provides regular trainings, seminars, and symposia to social workers and the helping professions on topics such as disaster mental health.

Although Valparaiso has a professional and well-trained volunteer fire service, police department, and emergency medical service, there is currently no coordinated emergency management or disaster management agency in either the Upper Hills community or the city, such as the US FEMA. It could be argued that FEMA had numerous issues during Hurricane Katrina in 2005; however, legislative changes, such as the Post-Katrina Emergency Management Reform Act of 2006, led to vast improvements in disaster response and recovery in numerous events since 2006, including Hurricane Sandy in 2012 (Office of Inspector General, 2013a, b). While it can be argued that 3 years after Hurricane Sandy some residents are still not able to rebuild, data and research demonstrate that FEMA provided assistance to over 200,000 residents at a cost of over one billion dollars and continues to assist citizens (Luckman, Strafer, \& Lipski, 2016). FEMA, having learned many valuable lessons from Hurricane Katrina, was more proactive during Hurricane Sandy, while still not perfect, it provided a much more community-based approach (Office of Inspector General, 2013b).

It was evident from this research (Luckman, et al., 2016) that some of the preparedness measures that would assist, along with basic building and land use codes, are missing in the Upper Hills communities. The residents are living on land that they do not own but, more importantly, on land that does not have proper land use planning and safety codes, and these issues, along with lacking infrastructure and having a fuel load that adds to the potential for future disasters for the vulnerable residents of the Upper Hills, still creates an environment for potential deadly future disasters. One of the commonalities that exists between the citizens of Valparaiso and the citizens of many disaster-affected areas in the USA is the citizen resilience at the most basic level rather than relying on the government. Whereas the squatters of the Upper Hills quickly began to rebuild, "it is the neighbors who are the first responders and who assemble the impromptu kitchens and networks to rebuild" (Solnit, 2009, p. 305). While this community-organized response is commendable and admirable, it alone cannot build capacity and governments in which these disasters occur must be held accountable.

A disaster preparedness plan not only builds capacity within the region and better prepares the residents and leaders of the Upper Hills to take an active role in response to the disaster but also holds the government accountable to care for all members of the society and not just those in the lower hills region, thus implementing a nondiscriminatory disaster plan. Following the 
September 16, 2015, earthquake in Chile, the news headline read, "Chile Earthquake: Disaster Planning Pays Off" (Shoichet \& Ramos, 2015). Earthquake and tsunamis are not the only threats to Chile, and in fact, our research showed that there are more fires occurring on a regular basis than earthquakes and tsunamis and the lack of preparedness plan hinders the response and recovery efforts and places all, including those reaching out to assist, in danger. In fact, a 23-year risk analysis study by faculty at the University of Chile noted that there were over 1000 fires per year and, while not all of those fires evolved into the type of fire that this study examined, they all had the potential as the conditions, terrain, and fuel load were present (Castillo, et al., 2012).

There is much the disaster response social worker can utilize from this study. In addition to considering a human rightsbased approach to interventions pre, during, and post disaster, education for citizens regarding how to effectively mobilize and access resources within the community to mitigate disaster's response is critical. The social worker must be aware of the sense of community and the willingness or lack thereof, to tap into critical disaster response resources for the affected individuals. The social worker must be familiar not only with disaster and recovery resources, but they need to be cognizant of the roles of informal leaders within a community, such as the Upper Hills, in order to speed up the recovery process. Post-disaster healing may be addressed by using a human rights-based approach to interventions, allowing citizens the ability to keep the community together and to access and express the rights in an area that has been seen as marginalized by its own government.

Educating citizens in a human rights-based approach to disaster management would involve social workers and community members creating programs that are driven by the local population. Implementing response plans that do not have community input is often doomed from the start (Halpern \& Tramontin, 2007). Citizens may refuse to buy in to any plan that does not take into account community members' thoughts, beliefs, and cultural values.

Utilizing the community members' thoughts, values, and cultural beliefs, social workers could drive human rights education by working with community centers and local citizens in designing disaster management plans that address the needs of the most vulnerable populations of their community in addition to establishing protocols in collaboration with first responders for physical safety and to address the human rights of the community residents following a disaster or trauma (Halpern \& Tramontin, 2007).

\section{Strengths/Limitations}

Given the extent of the fire and the number of individuals affected, it was not possible to gather data from individuals residing or working in all seven hills affected by the fire.
However, those hills most affected were examined, and interviews were conducted with the firefighters who were responsible for extinguishing the fires that ravaged across the hills. Therefore, we were able to obtain an emic perspective from those closest to the disaster. Despite the strength of obtaining an insider's perspective, it should be noted that the research team comprised members from the USA and, therefore, research participants may have been reluctant to share information with us. To control for this, we always had local interpreters present who were trusted by our participants, a key factor to consider when conducting cross-cultural research (Liamputtong, 2010).

Another limitation was the lack of time spent in country. One week in country did not afford the opportunity to monitor disaster response over a longer period of time; however, given Chile's history with disasters, participants were able to share how the response to this disaster was consistent or inconsistent with other responses. A particular strength of the study was the varied interviews/focus groups conducted to ensure data were collected from the key stakeholders (e.g., firefighters, psychosocial team members, mental health professionals, and residents). In addition, how a human rights-based approach to disaster management and recovery empowered citizens to strengthen their remote community is another strength of this study. There was much for a disaster response social worker to learn, not the least of which being the resilience and recovery of the citizens of the Upper Hills.

\section{Conclusion}

Change in communities, such as the Upper Hills, often occurs when it is driven from within (Ginsburg, 2014). The residents of the Upper Hills of Valparaiso responded quickly despite the amount of devastation caused by the Great Fire of 2014. The majority of the homes were rebuilt within 6 months of the fire. A human rights-based approach to disaster management needs to ensure adequate infrastructure is in place, which was lacking within the Upper Hills in April 2014, and continues to place the residents in this area at risk for another potential disastrous fire. Members of the Upper Hills community are at greater risk because of their vulnerable position within society; however, the development of the Latin America Council of IAEM and the future work of IAEM caucuses promises that the future for the Upper Hills of Valparaiso will be more equitable and just, as it relates to disaster management. The IAEM is a membershipdriven organization with membership coming from all levels of government and the private sector. Membership in IAEM gives all members access to the information they need to provide resources for involving all community stakeholders. Although Valparaiso is smaller in geographic size than many of South America's bigger metropolitan areas, the IAEM is large enough to assist all communities, while small enough to make sure that 
every community has access to the resources it needs. As the Latin American Council expands, all communities, large and small, will benefit. The IAEM has leadership from small and large organizations, all levels of government, which allows every emergency manager and associated agency equal access and opportunity. All caucuses and committees within the IAEM are membership driven, which allows the organization to attain the viewpoint of a variety of stakeholders. With the open enrollment and membership model, the IAEM encourages all members to get actively involved and participate in its many opportunities, which should help both large and small communities in the region (IAEM, 2017). The local disaster management leaders in Valparaiso and other small communities within Chile can utilize the IAEM's eight principles of emergency management and FEMA's whole community approach to furthering their human rights-based approach to disaster preparedness, response, and recovery. Both the IAEM and FEMA have many programs that include citizen involvement and education for successful outcomes. FEMA, through its various public outreach campaigns and training of emergency managers, continues to express the need for citizen involvement in their own successful outcomes before, during, and after a disaster. FEMA's (2014) citizen preparedness model of the whole community approach can be successfully witnessed as an analogy in what was demonstrated by the citizens of the Upper Hills following these devastating fires. FEMA understands that there will never be enough resources to provide complete and immediate disaster response and recovery for all citizens and that neighbors and neighborhoods, as Solnit (2009) highlights in her book, A Paradise Build in Hell, must come together in times of disasters. In addition, many social workers are now actively becoming educated in disaster response and recovery, which gives the local emergency managers another source for educating, networking, and expanding on the human rightsbased approach. In collaboration with Latin American Council of IAEM, the social workers can not only learn how to respond to a disaster such as the wildfires, but they can utilize the human rights-based approach to ensure the citizens who live in these remote, under-resourced communities, such as the Upper Hills, are engaged throughout the disaster preparedness, response, and recovery processes.

Acknowledgments Funding, in part, for this research was possible as result of a grant from the Pennsylvania State System of Higher Education, Faculty Professional Development Council.

\section{Compliance with Ethical Standards}

Ethical Approval All procedures performed in studies involving human participants were in accordance with the ethical standards of the institutional and/or national research committee and with the 1964 Helsinki Declaration and its later amendments or comparable ethical standards.

\section{References}

Arouri, M., Nguyen, C., \& Youssef, A. B. (2015). Natural disasters, household welfare and resilience: evidence from rural Vietnam. World Development, 70, 59-77.

Barrios, R. E. (2014). Here, I'm not at ease: anthropological perspectives on community resilience. Disasters, 38, 329-350.

Bergstrand, K., Mayer, B., Brumback, B., \& Zhang, Y. (2015). Assessing the relationship between social vulnerability and community resilience to hazards. Social Indicators Research, 122, 391-409.

Bonnefoy, P. (2014). After fire, picturesque hills of Chilean port city are left in ruins. New York Times. Retrieved from https://www.nytimes. com/2014/04/15/world/americas/after-fire-picturesque-hills-ofchilean-port-city-are-left-in-ruin.html.

Castillo, M., Quintanilla, V., \& Guillermo, J. (2012). Risk analysis and vulnerability against forest fires in areas of interface, Province of Valparaiso. Applied Geography, 35, 199-207.

Concannon, B., \& Lindstrom, B. (2012). Cheaper, better, longer-lasting: a rights-based approach to disaster response in Haiti. Emory International Law Review, 25, 1145-1191.

Cox, R. S., \& Hamlen, M. (2015). Community disaster resilience and the rural resilience index. American Behavioral Scientist, 59, 220-237.

Cutter, S. L., Ash, K. D., \& Emrich, C. T. (2014). The geographies of community disaster resilience. Global Environmental Change, 29, 65-77.

Denzin, N. K., \& Lincoln, Y. S. (Eds.). (2005). The handbook of qualitative research (3rd ed.). Thousand Oaks: SAGE.

Ensor, J. E., Park, S. E., Hoddy, E. T., \& Ratner, B. D. (2015). A rights based perspective on adaptive capacity. Global Environmental Change, 31, 38-49.

Federal Emergency Management Agency. (2014) Whole community. Retrieved from https://www.fema.gov/whole-community.

Federal Emergency Management Agency. (2017). Welcome to national preparedness. Retrieved from https://training.fema.gov.

Fernando, G. A. (2012). Bloodied but unbowed: resilience examined in a South Asian community. American Journal of Orthopsychiatry, 82, 367-375.

Garfin, D., Silver, R., Gil-Rivas, V., Guzmán, J., Murphy, J., Cova, F., et al. (2014). Children's reactions to the 2010 Chilean earthquake: the role of trauma exposure, family context, and school-based mental health programming. Psychological Trauma: Theory, Research, Practice \& Policy, 6(5), 563-573. https://doi.org/10.1037/ a0036584.

Gibbs, L., Waters, E., Bryant, R. A., Pattison, P., Lusher, D., Harris, L., et al. (2013). Beyond bushfires: community resilience and recoverya longitudinal mixed method study of the medium to long term impacts of bushfires on mental health and social connectedness. BMC Public Health, 13(1036).

Ginsburg, L. (2014). Introduction to basic concepts of rural social work. In L. Ginsburg (Ed.), Social Work in Rural Communities. Arlington: Council on Social Work Education.

Government of Chile, National Emergency Bureau, Ministry of the Interior. (n.d.). Basic integral security guide for visitors and foreign residents in Chile. Retrieved from https://www.santiago.diplo.de/ contentblob/422340/Daten/14470/PDF_Handbuch_ONEMI_ englisch.pdf.

Gupta, R. (2015). Disaster management. International Journal of Nursing Education, 7, 100-105.

Halpern, J., \& Tramontin, M. (2007). Disaster mental health: theory and practice. Independence: Thomson, Brooks/Cole.

Homad- Hanan, G. (2009). Central Chile has lost $38 \%$ of its forests between 1975 and 2008. Santiago Times. Retrieved from https:// www.worldaffairsjournal.org/content/deforestation-chile.

Human Rights Center. (2011). Natural disasters and human rights: comparing responses to Haiti and Pakistan. Retrieved from: https:// 
www.bc.edu/content/dam/files/centers/humanrights/pdf/CHRIJ\% 20newsletter\%20Winter\%202010-11.pdf.

International Association of Emergency Managers. (2015). Retrieved from https://www.iaem.com/page.cfm?p=council/lac/news\&lvl=2

International Association of Emergency Managers. (2017). Retrieved from https://www.iaem.com/.

Jarroud, M. (2014). Valparaiso blaze highlights the city's poverty. Retrieved from https://www.ipsnews.net/2014/04/valparaiso-blazehighlights-citys-poverty/.

Johnson, V. (2010). Are children's perspectives valued in changing contexts? Revisiting a rights based evaluation in Nepal. Journal of International Development, 22, 1076-1089.

Korstanje, M. E. (2014). Chile helps Chile: exploring the earthquake of 2010. International Journal of Resilience in the Built Environment, 5, 380-390.

Liamputtong, P. (2010). Performing qualitative cross-cultural research. New York: Cambridge University Press.

Luckman, M. H., Strafer, D., \& Lipski, C. (2016). Three years later, Sandy survivors remain homeless. Touro Law Review, 32, 313-339.

Magsino, S. (2009). The application of social network analysis for building community disaster resilience: workshop summary. Washington, D.C.: National Research Council.

Manyena, S. B., \& Gordon, S. (2015). Bridging the concepts of resilience, fragility and stabilization. Disaster Prevention and Management, $24,38-52$.

Martinez, R. (2017). Chile's forest fires have been raging for weeks. What caused them? Global Post. Retrieved from https://www.pri.org/ stories/2017-02-10/chiles-forest-fires-have-been-raging-weeksnow-why?.

National Association of Social Workers. (2008). Code of ethics. Retrieved from https://socialworkers.org/pubs/code/default.asp. Accessed December 7, 2016.

National Geographic. (2017). The worst wildfires in Chile's history revealed in pictures. Retrieved from https://news.nationalgeographic. com/2017/01/chile-wildfires-photos/. Accessed December 7, 2016.

Office of Inspector General, United States Department of Homeland Security. (2013a). FEMA's initial response in New Jersey to Hurricane Sandy. Washington, DC: Government Printing Office.

Office of Inspector General, United States Department of Homeland Security. (2013b). FEMA's initial response in New York City to Hurricane Sandy. Washington, DC: Government Printing Office.

Organization of Cooperation and Economic Development (2017). About the OECD. Retrieved from https://oecd.org/about.
QSR International. (2011). NVivo 9.0.

Reichert, E. (2011). Social work and human rights: a foundation for policy and practice (2nd ed.). New York: Columbia University Press.

Reska, P., \& Fuentes, A. (2015). The Great Valparaiso Fire and fire safety management in Chile. Fire Technology, 51, 753-758.

Sandoval, V., Gonzalez-Muzzio, C., \& Albornoz, C. (2014). Resilience and environmental justice: potential linkages. Procedia Economic Finance, 18, 416-424.

Shoichet, C., \& Ramos, A., (2015). Chile earthquake: disaster planning pays off. Retrieved from https://cnn.com/2015/09/17/americas/ chile-earthquake.

Social Work Management. (2015). Social work management in Chile. Retrieved from https://socialworkmanager.org/press-blogs/news/ social-work-management-in-chile/.

Solnit, R. (2009). A paradise built in hell. New York: Penguin.

Townshend, I. (2015). Social cohesion and resilience across communities that have experienced a disaster. Natural Hazards, 76, 913-938.

Trochim, W. (1989). Outcome pattern matching and program theory. Evaluation and Program Planning, 12, 355-366.

United Nations. (1948). Universal declaration of human rights. New York: Author.

United Nations Educational, Scientific and Cultural Organization. (2003). Historic quarter of the seaport city of Valparaiso. Retrieved from https://whc.unesco.org/en/list/959/. Accessed December 7, 2016.

United Nations Educational, Scientific and Cultural Organization. (2014). Director-General offers UNESCO's support for Chile in the face of devastating fires in Valparaiso. Retrieved from https://whc.unesco. org/en/news/1120/. Accessed December 7, 2016.

United Nations High Commissioner for Human Rights. (2013). Human rights in post-disaster and post-conflict situations. Retrieved from https://www.ohchr.org/EN/HRBodies/HRC/AdvisoryCommittee/ Pages/HRpostdisasterandpostconflictsituations.aspx. Accessed December 7, 2016.

Ward, K., Hayden, T., Richard, L., Jennings, L., Loney, M., \& Young, E. (2015). The resilience of a community. Reflections, 19, 20-28.

Xin, H., Aronson, R., Lovelace, K. A., Strack, R., \& Villalba, J. A. (2014). Vietnamese refugees perspective on their community's resilience in the event of a natural disaster. International Journal of Mass Disasters and Emergencies, 32, 508-531.

Yin, R. K. (2009). Case study research: design and methods (4th ed.). Los Angeles: SAGE. 